\title{
Numerical Simulation Study on the Effects of Oil Spill Diffusion in The Qitou Sea Area
}

\author{
Jianfeng $\mathrm{Gao}^{1,2, *}$ and Qiliang $\mathrm{Mei}^{1}$ \\ ${ }^{1}$ United National-Local Engineering Laboratory of Harbor Oil and Gas Storage and Transportation Technology, Zhejiang, China \\ ${ }^{2}$ School of Petrochemical Engineering \& Environment, Zhejiang Ocean University, Zhejiang, China
}

\begin{abstract}
A two-dimensional hydrodynamic mathematical model of the sea area near the Qitou sea area was established by using MIKE21 hydrodynamic module, and the tidal level, flow velocity and direction simulated by the hydrodynamic model were verified according to the measured data. Based on MIKE21 hydrodynamic model and particle tracking module, a mathematical model of oil spill diffusion centered on the sea area of Qitou was established, and the influence range of oil spill under six different working conditions and the time of oil spill reaching the main sensitive area near The sea area of Qitou were simulated. The analysis shows that tidal current and wind are the main factors affecting the diffusion process of oil spill in The Qitou sea. The calculation results show the influence area of oil spill 24 hours after the occurrence of the accident and the time when the oil spill reaches the main sensitive area in The sea area of Qitou, which has a certain guiding role in dealing with the offshore oil spill pollution and formulating the emergency treatment plan of oil spill accident in the sea area of Qitou.
\end{abstract}

\section{The introduction}

The Qitou sea area is located in the northeastern part of Zhejiang Province, surrounded by Chuanshan Peninsula in the south, Chuanbi Island in the west, Ant Island in the east, Meishan Island in the southwest, and Xiaogan Island in the northeast. It is an important aquaculture area, tourism development zone and biological nature reserve in Zhejiang Province. With the construction of the oil storage base on Aoshan Island in Zhoushan, the volume of regional vessel traffic has increased rapidly, resulting in an increasing risk of accidental oil spills.Oil spill pollution will seriously affect the marine ecological environment and the development of normal industry, fishery and tourism in the vicinity of the pollution source.

In order to reduce the impact of oil spill on the marine environment, many scholars at home and abroad have done a lot of research on the drift and diffusion law of oil film after oil spill ${ }^{[1-5]}$. Elliot et al. proposed the random walk theory, regarding the diffusion process of oil spill as the random walk process of a large number of oil particles, and taking into account a series of complex influencing factors such as the evaporation and settlement of oil particles in water ${ }^{[6]}$. M. Faghihifard et al. combined the influence of wind, tidal current and temperature on oil spill diffusion to simulate the oil spill in the Persian Gulf and verified the simulation results ${ }^{[7]}$. S. Liubartseva et al. carried out numerical simulation of the Ulysses oil spill in October 2018, compared the simulation results with satellite observation data, and further analyzed the impact range of the oil spill ${ }^{[8]}$. At home, many scholars have carried out a large number of oil spill simulation studies in many seas in China ${ }^{[9-14]}$. Based on the MIKE 21 module, Qi Qinghui et al. established an oil spill model for the northern section of the Beijing-Hangzhou Canal and predicted the diffusion of oil particles after the oil spill accident ${ }^{[15]}$.Wu Fanjie et al. established a threedimensional hydrodynamic model to simulate the spread of oil spill in the Xiangshan Port sea area, and pointed out that tidal current is the main factor affecting the trajectory of oil spill, and wind conditions are an important factor affecting the area of oil spilled oil film ${ }^{[16]}$.

In this study, hydrodynamic module (HD) and particle tracking module (PT) in MIKE 21 developed by DHI were used to establish the mathematical model of oil spill diffusion in the Qitou sea area. The oil spill model is mainly used to obtain the corresponding flow field data through the hydrodynamic model, and then coupled various influencing factors affecting the oil film drift, so as to simulate the migration and diffusion process of oil spill accidents.

\section{Hydrodynamic model of the Saitou Ocean}

\subsection{Governing equation}

The model is based on the Navier-Stokes equation and is subject to the assumption of Boussinesq and hydrostatic pressure. It provides a data basis for the application of other modules. The governing equation of the model is calculated in the plane cartesian coordinate system as follows:

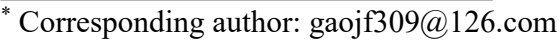


Continuity equation:

$$
\frac{\partial h}{\partial t}+\frac{\partial h \bar{u}}{\partial x}+\frac{\partial h \bar{v}}{\partial y}=h S
$$

$\mathrm{X}$-direction momentum equation:

$\frac{\partial h \bar{u}}{\partial t}+\frac{\partial h \bar{u}^{2}}{\partial x}+\frac{\partial h \bar{v} \bar{u}}{\partial y}=f \bar{v} h-\mathrm{g} h \frac{\partial \eta}{\partial x}-\frac{h}{\rho_{0}} \frac{\partial p_{a}}{\partial x}-\frac{\mathrm{g} h^{2}}{2 \rho_{0}} \frac{\partial \rho}{\partial x}+$

$\frac{\tau_{s x}}{\rho_{0}}-\frac{\tau_{b x}}{\rho_{0}}-\frac{1}{\rho}\left(\frac{\partial S_{x x}}{\partial x}+\frac{\partial S_{x y}}{\partial y}\right)+\frac{\partial}{\partial x}\left(h T_{x x}\right)+\frac{\partial}{\partial x}\left(h T_{x y}\right)+$

$h u_{s} S$

$\mathrm{X}$-direction momentum equation:

$\frac{\partial h \bar{v}}{\partial t}+\frac{\partial h \overline{u v}}{\partial x}+\frac{\partial h \bar{v}^{2}}{\partial y}=-f \bar{u} h-\mathrm{g} h \frac{\partial \eta}{\partial y}-\frac{h}{\rho_{0}} \frac{\partial p_{a}}{\partial y}-\frac{\mathrm{g} h^{2}}{2 \rho_{0}} \frac{\partial \rho}{\partial y}+$ $\frac{\tau_{s y}}{\rho_{0}}-\frac{\tau_{b y}}{\rho_{0}}-\frac{1}{\rho_{0}}\left(\frac{\partial S_{y x}}{\partial x}+\frac{\partial S_{y y}}{\partial y}\right)+\frac{\partial}{\partial x}\left(h T_{x y}\right)+\frac{\partial}{\partial y}\left(h T_{y y}\right)+$ $h v_{S} S$

In Equations $(1 \sim 3)$ : $t$ is time (s); $\eta$ is water level (m); $d$ is still water depth; $h$ is the total water depth (m); $u$ and $v$ are the velocity components $(\mathrm{m} / \mathrm{s})$ in the $\mathrm{x}$ and $\mathrm{y}$ directions respectively; $f$ is the coefficient of Coriander force; $g$ is the acceleration due to gravity $\left(9.8 \mathrm{~m} / \mathrm{s}^{2}\right) ; \rho$ is the density of water $\left(\mathrm{kg} / \mathrm{m}^{3}\right) ; S_{x x}, S_{x y}, S_{y y}$ are radiation stress components respectively; $S$ is the unit volume discharge of the source; $\bar{u}$ and $\bar{v}$ is the average flow velocity.

\subsection{Numerical Simulation}

The model calculation range of this study is sea area of $120.9^{\circ}-123.3^{\circ}$ East longitude and $29.0^{\circ}-30.9^{\circ}$ North latitude. The terrain and oil spill point locations in the calculation area are shown in Figure 1. Coastline is taken from Google map and triangular grid constructed by SMS software, which can accurately simulate the underwater terrain features of this area.. At the same time, in order to facilitate the calculation, the grid is relatively sparse in the open sea and dense in the offshore and simulated areas. The open boundary tidal level conditions of the model are obtained by the global tidal prediction model.

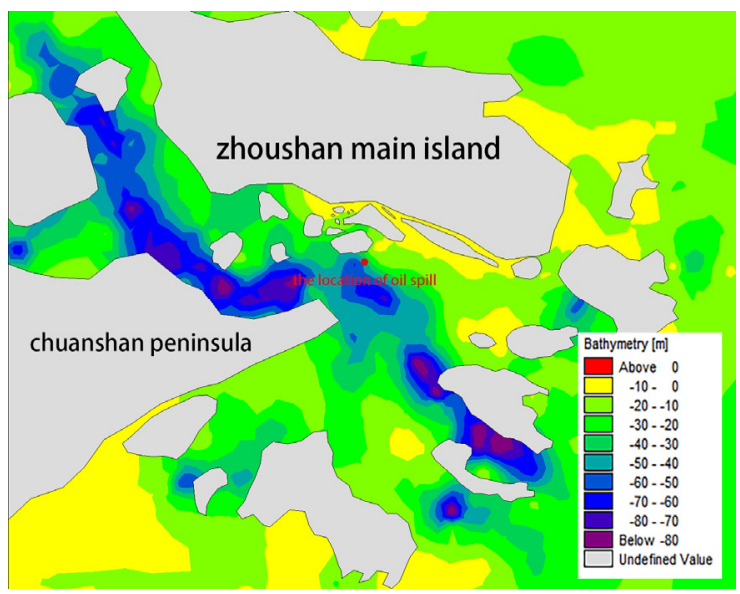

Figure 1. Computational Domain topography and oil spill location

The accuracy of the model was verified by comparing the measured values of The Shenjiamen tidal level station (T1) and the three ocean current observation stations (N1, N2, and N3) in the Qitou Sea area with the calculated values of the simulated results. The locations of T1, N1, $\mathrm{N} 2$ and N3 are shown in Figure 2. The validation data are the hydrologic data measured in Shenjiamen from March to April 2017. Figure 3and4 show the comparison between measured and calculated values of tide level, velocity and flow direction during spring tide. The measured and calculated values are basically consistent, which indicates that the hydrodynamic model established can well simulate the tidal current movement process in the Qitou sea area.

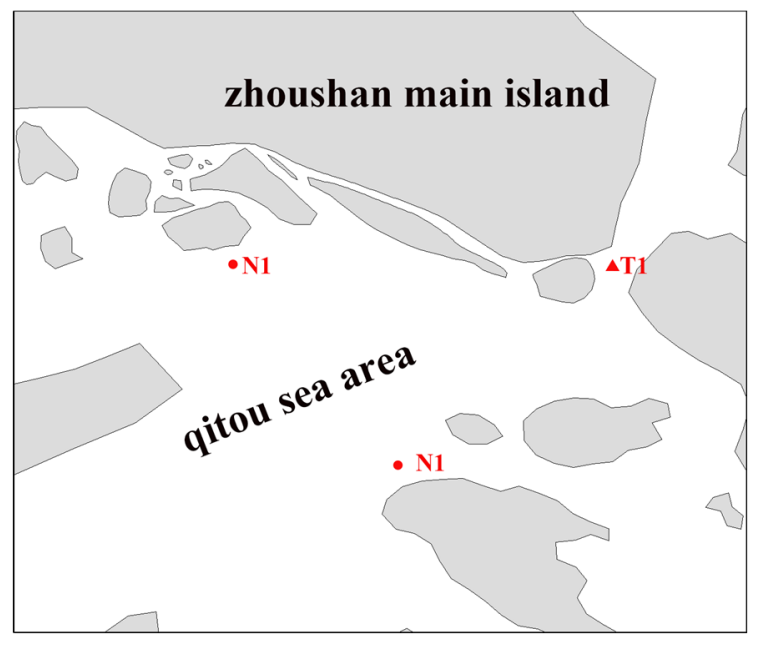

Figure 2. Position of tidal station and current observation station

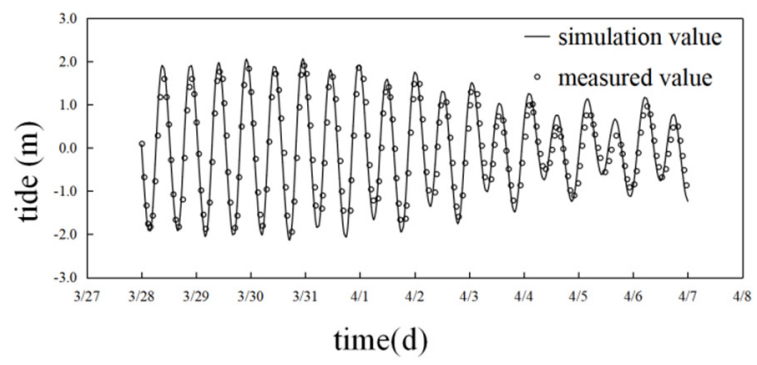

Figure 3. Comparison results of simulation and measured tidal level values 


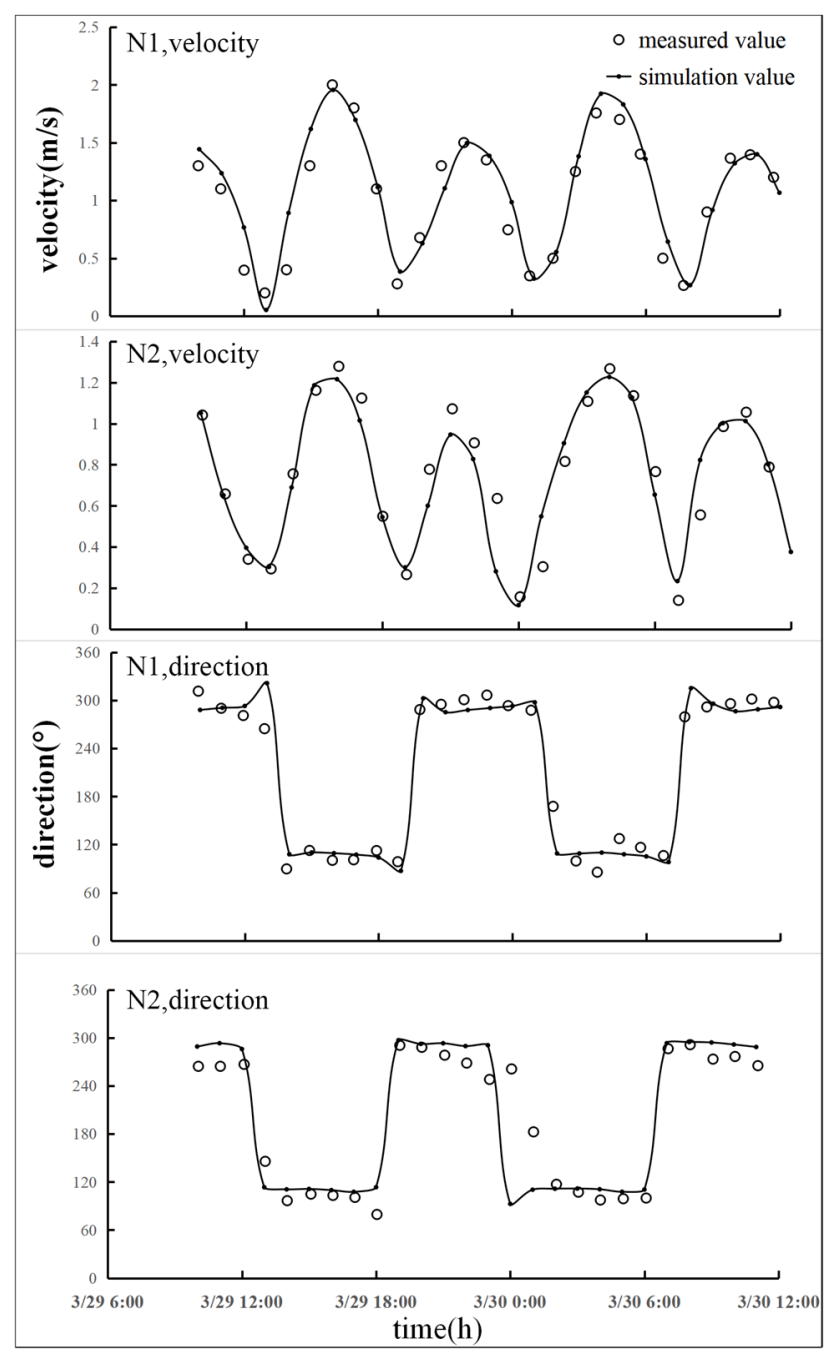

Figure 4. Comparison results of measured and measured flow rate and flow direction

\section{Oil spill impact prediction in Qitou Sea area}

\subsection{Overview of oil spill simulation}

The oil particle model uses Lagrange random walking method and particle cloud principle to describe the process of oil spill diffusion. Firstly, the hydrodynamic model is used to obtain the time and space changes of water depth and flow field in the full computational domain. On this basis, the oil spill is regarded as a large number of oil particles. By tracking a large number of spilled oil particles, the movement process and its destination of oil particles under the influence of external environment after the occurrence of oil spills are studied.

Modified Fay gravity-viscosity formula is adopted for oil film expansion:

$$
\frac{\mathrm{dA}_{\mathrm{o}}}{\mathrm{dt}}=\mathrm{K}_{\mathrm{a}} \mathrm{A}_{\mathrm{o}}^{1 / 3}\left(\frac{\mathrm{V}_{\mathrm{o}}}{\mathrm{A}_{\mathrm{o}}}\right)^{4 / 3}
$$

In Equation (4), $A_{o}$ is the oil film area $\left(\mathrm{m}^{2}\right), V_{o}$ is the volume of oil block $\left(\mathrm{m}^{3}\right), \mathrm{K}$ is the coefficient, $t$ is the time (s).

The velocity equation of the drift motion of oil particles is as follows:

$$
\mathrm{U}_{\mathrm{t}}=\mathrm{C}_{\mathrm{W}} \mathrm{U}_{\mathrm{W}}+\mathrm{U}_{\mathrm{S}}
$$

With i $\Delta \mathrm{T}$ time, the position of the oil particle changes to:

$$
\begin{aligned}
& \mathrm{X}=\mathrm{X}_{0}+\mathrm{u} \Delta \mathrm{t}+\mathrm{C}_{\mathrm{W}} \mathrm{U}_{\mathrm{W}} \sin \theta \Delta \mathrm{t} \\
& \mathrm{Y}=\mathrm{Y}_{0}+\mathrm{v} \Delta \mathrm{t}+\mathrm{C}_{\mathrm{W}} \mathrm{U}_{\mathrm{W}} \cos \theta \Delta \mathrm{t}
\end{aligned}
$$

In Equation (5 7) : $U_{t}$ is the total drift velocity of oil particles $(\mathrm{m} / \mathrm{s}) ; \mathrm{U}_{\mathrm{w}}$ is the wind speed at $10 \mathrm{~m}$ above the sea surface $(\mathrm{m} / \mathrm{s}) ; \mathrm{C}_{\mathrm{w}}$ is the wind conductivity coefficient; $\mathrm{U}_{\mathrm{s}}$ is the sea surface velocity $(\mathrm{m} / \mathrm{s}) ; X_{0}, Y_{0}$ is the initial position of the oil particle, $U_{t}$ is the total drift velocity $(\mathrm{m} / \mathrm{s}), \mathrm{U}_{\mathrm{s}}$ is the surface velocity $(\mathrm{m} / \mathrm{s}), u$ and $v$ are the velocity in the $x$ and $y$ directions $(\mathrm{m} / \mathrm{s}), U_{w}$ is the wind speed at $10 \mathrm{~m}$ over the sea $(\mathrm{m} / \mathrm{s}), \theta$ is the wind direction Angle, $\mathrm{C}_{\mathrm{w}}$ is the wind drift coefficient.

\subsection{Oil spill parameters and operating conditions}

In this paper, the oil spill in Qitou sea area occurred near the southern wharf of Aoshan Island in Zhoushan. The main sensitive targets in the waters of Qitou include the three tourist areas of Ant Island, Taohua Island and Zhujiajian, as well as the Reserve 1 and 2. The specific locations are shown in Figure 5. The type of oil spill was $50 \mathrm{t}$ crude oil that continued to leak for $30 \mathrm{~min}$. In the oil spill model, the amount of oil spill was expressed by 9000 "oil particles". Two typical tidal periods, rising and falling, were selected as the initial time of oil spill. Three different wind conditions are considered according to the wind data of Qitou sea area: still wind; Normal wind, SE wind direction, $5.22 \mathrm{~m} / \mathrm{s}$; Adverse wind, NNE wind, $3.5 \mathrm{~m} / \mathrm{s}$. There are six results in the numerical simulation of oil spill, and the calculation time is 24 hours.

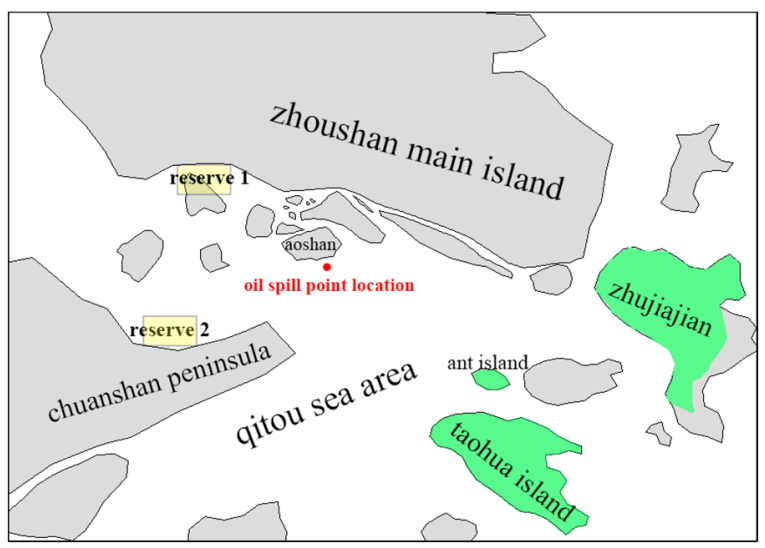

Figure 5. Oil spill location and the main sensitive targets

\subsection{Prediction and analysis of the impact of oil spill diffusion}

This paper focuses on the study of the influence scope of oil spill within $24 \mathrm{~h}$ after the occurrence of oil spill and its influence on the sensitive area in the surrounding sea area. 


\subsubsection{Analysis of the impact area of oil spill}

At two tides of rising and falling tides, the influence range of oil spill within 24 hours after oil spill occurred under three wind conditions is shown in Figure 7. Under the condition of still wind, the oil film generally migrates and diffuses to the surrounding sea under the action of tidal current. Under normal wind, affected by tidal currents an SE winds, the oil film will drift to the northwest and be absorbed by the shoreline when it diffused to the south of Zhoushan island. Under the unfavorable NNE wind conditions, the oil film is slightly shifted to the west and north, and its influence range is larger than that under the still wind conditions.

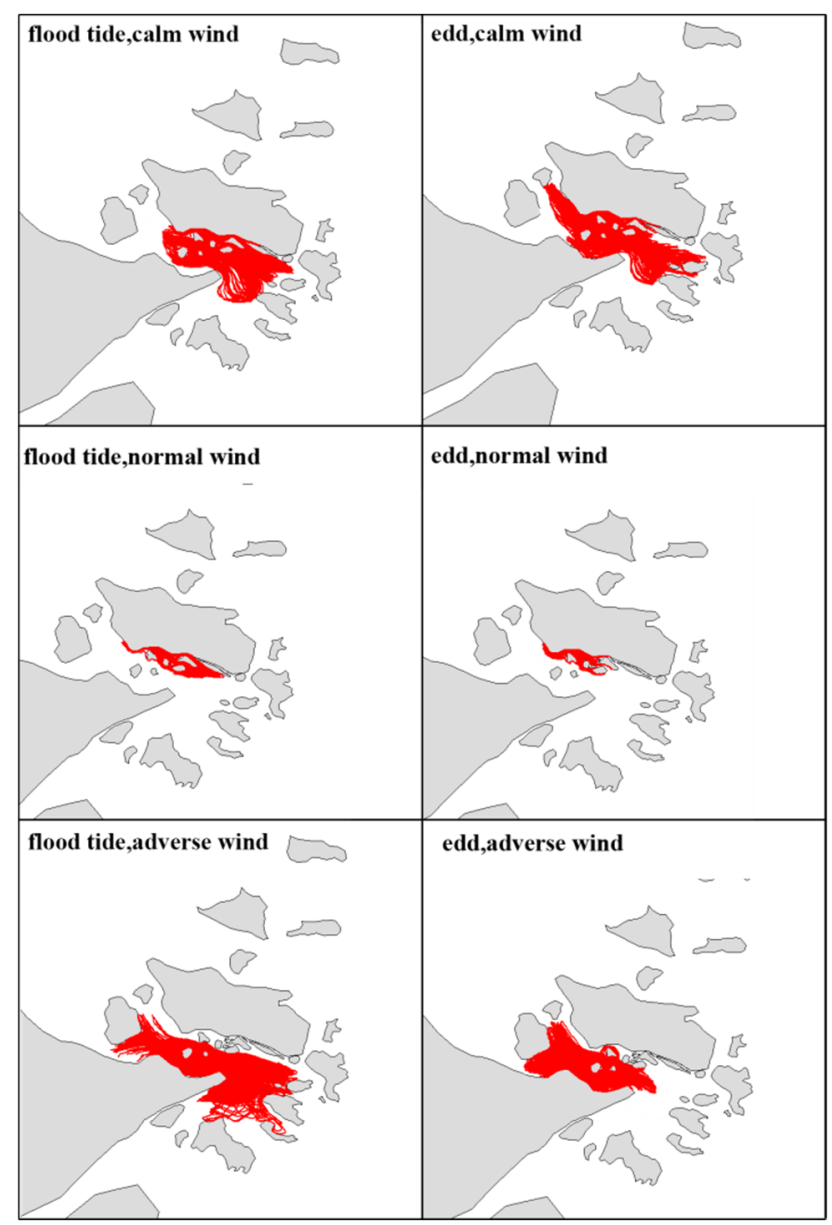

Figure 6. Influence range of oil spill in $24 \mathrm{~h}$ under different working conditions

\subsubsection{The impact of oil spill on the surrounding sensitive areas}

The occurrence of oil spill will seriously affect the Marine environment in the sensitive area of the surrounding sea. The prediction of the time when the oil film reaches the sensitive area can provide a scientific basis for the formulation of emergency measures for oil spill accidents. The time of oil spill arriving at each major sensitive area in Qitou sea area within 24h after oil spill occurred is shown in Table 1.
Table1: Time for oil film to reach the sensitive area within $24 \mathrm{~h}$ after oil spill occurs

\begin{tabular}{|c|c|c|c|c|c|c|}
\hline \multirow{2}{*}{ Situation } & \multicolumn{5}{|c|}{ Time to reach the main sensitive area /h } \\
\cline { 2 - 7 } & $\begin{array}{c}\text { Ant } \\
\text { islan } \\
\text { d }\end{array}$ & $\begin{array}{c}\text { Taohua } \\
\text { island }\end{array}$ & $\begin{array}{c}\text { Zhu } \\
\text { jiaji } \\
\text { an }\end{array}$ & $\begin{array}{c}\text { Reserve } \\
1\end{array}$ & $\begin{array}{c}\text { Reserve } \\
2\end{array}$ \\
\hline \multirow{2}{*}{$\begin{array}{c}\text { No } \\
\text { wind }\end{array}$} & $\begin{array}{c}\text { Flood } \\
\text { tide }\end{array}$ & 17.25 & 18.25 & - & 11 & 24 \\
\cline { 2 - 7 } & Edd & 11.5 & 12 & - & 5 & 19 \\
\hline \multirow{2}{*}{$\begin{array}{c}\text { Nor } \\
\text { mal } \\
\text { wind }\end{array}$} & $\begin{array}{c}\text { Flood } \\
\text { tide }\end{array}$ & - & - & - & 9.75 & - \\
\cline { 2 - 7 } & Edd & - & - & - & 4.25 & - \\
\hline $\begin{array}{c}\text { Adve } \\
\text { rse } \\
\text { wind }\end{array}$ & $\begin{array}{c}\text { Flood } \\
\text { tide }\end{array}$ & 4.25 & 5 & - & - & 15 \\
\cline { 2 - 7 } & Edd & - & - & - & 4.5 & 9.75 \\
\hline
\end{tabular}

Note: "-" means that the oil film does not reach the sensitive area within 24 hours

It can be seen from Table 1 that after the oil spill, under the action of tide and wind, the oil film can reach The Scenic Area of Ant Island, Taohua Island, Reserve 1 and Reserve 2 within 24 hours, while it has no impact on the scenic area of Zhujiajian in the east. Under the still wind condition, the oil film will reach Reserve 1 within 5 hours, reach the Ant Island scenic area within 11.5 hours, and reach the Taohua Island scenic area within 12 hours. Under normal wind (SE) conditions, due to the influence of wind, the oil film will reach Reserve 1 after $4.25 \mathrm{~h}$ and will be absorbed by the shoreline, so it will not affect other sensitive areas. Under the NNE wind conditions, the oil spill occurred at different tidal and affected different areas. At high tide, the oil film reaches Ant Island, Taohua Island scenic area and Reserve 1. At low tide, the oil film does not reach the three scenic areas, but will reaches Reserve 1and Reserve 2.

By analyzing the oil spill simulation results under six representative working conditions, it can be seen that the oil spill diffusion in the Qitou sea area is mainly affected by tidal current and wind. Due to the different hydrodynamic environment around the oil spill point, the oil film movement path and diffusion range are different when the oil spill occurs at different tides. At the same time, different wind direction and wind speed will affect the direction of oil film movement. Under normal wind conditions, the oil film will drift northwestward and gradually adsorb to the shoreline, with a relatively small range of influence. Under unfavorable wind conditions, the oil film will drift to the south, and the oil film under this wind condition will first affect the two tourist areas located in the southeast of the oil spill point.

\section{CONCLUSION}

Based on MIKE21, a hydrodynamic model and an oil spill diffusion model in the Qitouyang area were established, and the oil spill accidents that may occur during the passage of the southern oil terminal of Aoshan Island were simulated and predicted. The drift path and diffusion range of the oil film under six different situations are simulated. The simulation results show that the oil spill in Qitou sea area will not affect the Zhujiajian Scenic Area in the east of the oil spill point within 24 hours, and the 
drift process is mainly affected by tidal current and wind. The results of numerical simulation and prediction can provide scientific basis for the treatment of oil spill pollution and provide guidance for the formulation of emergency treatment plan of oil spill accident in the Qitou sea area.

\section{About the author}

Gao Jianfeng, male, associate professor, born in 1966, graduated from the College of Logistics Engineering in 2008, majoring in oil and gas storage and transportation engineering. Now he is engaged in the research of oil and gas safety technology. Address: 1 Haida South Road, Lincheng Street, Dinghai District, Zhoushan city, Zhejiang Province, 316022.Contact number: 13567693952, Email: gaojf309@126.com

\section{Acknowledgement}

Fund project: Zhoushan Science and Technology Bureau research project "Research on the Leak Detection and Monitoring System of Submarine Oil and gas Transmission Pipeline Based on Wavelet Analysis", 2017 C41004.

\section{References}

1. M. Reed, Ø. Johansen, P.J. Brandvik, P. Daling, A. Lewis, R. Fiocco, D. Mackay, R. Prentki, Oil Spill Modeling towards the Close of the 20th Century: Overview of the State of the Art. Spill Science and Technology Bulletin, 5 (1999)

2. H.Li, W.Z.Shao, C.Li, S.Zhang, W.S.Li, S.S.Xu, Research progress on prediction technology of oil spill expansion, drift and diffusion. Ocean bulletin,36,(2017)

3. K.A. Korotenko, R.M. Mamedov, C.N.K. Mooers, Prediction of the Transport and Dispersal of Oil in the South Caspian Sea Resulting from Blowouts. Environmental Fluid Mechanics, 1 (2001)

4. W.J. Lehr, H.M. Cekirge, R.J. Fraga, M.S. Belen, Empirical studies of the spreading of oil spills. Oil and Petrochemical Pollution, 2 (1984).

5. N.I. D, Y.P. D, Calculation of oil droplet size distribution in ocean oil spills: A review. Marine pollution bulletin, 135 (2018)

6. E. A.J., EUROSPILL: Oceanographic processes and NW European shelf databases. Elliott A.J, 22 (1991).

7. M. Faghihifard, M.A. Badri, Simulation of oil pollution in the Persian Gulf near Assaluyeh oil terminal. Marine Pollution Bulletin, 105 (2016)

8. S. Liubartseva, M. Smaoui, G. Coppini, G. Gonzalez, R. Lecci, S. Cretì, I. Federico, Model-based reconstruction of the Ulysse-Virginia oil spill, October-November 2018. Marine Pollution Bulletin, 154 (2020)
9. W.Q.Du,Numerical Simulation and THREEDIMENSIONAL Visualization of offshore Oil Spill (Dalian Maritime University,2020)

10. W.B.Lin, X.Y.Chen, J.H.Li, Simulation analysis of oil spill in adjacent waters of xuwei port area. J. Ocean forecast,37(2020)

11. Z.G.Gao, C.Li, H.Li, G.S.Wang, Research on prediction Methods of offshore oil spill drift and diffusion -- Taking Jiaozhou Bay Oil spill event as an example. J. China Ocean Bulletin,39(2020)

12. G.Fu, Numerical Simulation study on the Impact Analysis of oil spill accident in the sea area of a port project. J. China Water Transport. Fairway Science and Technology,5(2019)

13. T.Xie, B.S.Wang, Y.F.Gu, Y.1.Ni, W.Chen, Numerical simulation of oil spill from zhoushan reclamation project ship. J. China maritime navigation,42(2019)

14. J.Guo, S.Y.Kong, H.Yang, B.B.Pan, W.C.Cui, W.zhang, Simulation of offshore oil spill risk and its impact on sensitive areas of the surrounding environment. J. Bulletin of Marine Lakes and Marshes,04(2019)

15. Q.H.Qi, P.H.Dong, H.L.Qu, W.Xiong, Numerical simulation of oil spill diffusion in the subei section of the beijing-hangzhou canal. J. Watercourse and port,36(2015)

16. F.J.Wu, G.F.Wu, P.Dong, K.F.Zhang. Numerical Simulation of Oil Spill in Xiangshan Port. A. China Ocean Engineering Society.Proceedings of the 19th China Marine (Coastal) Engineering Symposium (ii). C. Chinese Ocean Engineering Society: Marine Engineering Branch of Chinese Ocean Society,7(2019) 